\title{
Emotional Intelligence: Which Traits Are Most Prized?
}

\section{Peter Hernon and Nancy Rossiter}

\begin{abstract}
Leadership encompasses self-management and managing relationships with others. Such a characterization is best known as emotional intelligence. This article identifies the traits that comprise emotional intelligence and suggests which ones might be most important for library directors to possess. The article also compares the emerging set of traits to transformational and transactional leadership in an effort to suggest which traits apply to two other leadership styles.
\end{abstract}

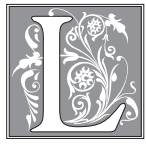

eadership focuses on social influence-influencing others to attain group, organizational, and societal goals. However, it is not a function confined solely to library directors and their senior management team; leadership should be evident at all levels of the organization. "Leadership," as A. J. Anderson, professor emeritus at Simmons College, commented, "needs to be adaptive. Group members and situations all influence a leader's effectiveness." ${ }^{1}$ Leadership is a complex matter, one that involves mastery of a number of traits and an ability to apply different leadership styles. Skill in the practice of leadership is gained "by 'doing' and reflecting on what is being learned." 2

Leadership, which has more than a hundred definitions, ${ }^{3}$ is becoming critically important for senior management as well as, for that matter, many other librarians to possess. J. Richard Hackman, the Cahners-Rabb Professor of Social and Organizational Psychology at Harvard
University, has commented that "leading a team is an emotionally demanding undertaking, especially in dealing with anxieties - both one's own and those of others." Leaders at all levels of an organization require emotional maturity to deal with these anxieties. ${ }^{4}$

Daniel Goleman, who popularized the term emotional intelligence (EI), showed that its possession is directly linked to leadership effectiveness. ${ }^{5}$ He characterized EI as managing the mood of the organization and as the "sine qua non of leadership." ${ }^{6}$ The five categories of emotional intelligence he identified are selfawareness, self-regulation, motivation, empathy, and social skill. The first three categories relate to self-management; the other two address managing relationships with others. ${ }^{7}$

\section{Problem Statement}

Previous research has explored the traits that successful academic and public library directors need to have and demonstrate. ${ }^{8-13}$ No study has recast those

Peter Hernon is a Professor in the Graduate School of Library and Information Science at Simmons College: e-mail: peter.hernon@simmons.edu. Nancy Rossiter is an Assistant Professor in the Graduate School of Library and Information Science at Simmons College: e-mail: nancy.rossiter@simmons.edu. 
traits in terms of EI. How comprehensive is the list of traits? Which ones do library directors perceive as being most important? Secondary questions include: Can the traits be learned? Which individuals are perceived as exhibiting them? How important is leadership as reflected in a set of traits in hiring new directors?

As Goleman explains, "having a welldeveloped emotional intelligence, both for the individual and for the organization, make it worth the effort."14 Such intelligence is an essential part of the effective performance of leaders, and "a leader's job is to provide that recognition of roles and functions within the group that will permit each member to satisfy and fulfill some major motive or interest," thereby contributing to the maturity of the organization. ${ }^{15}$

\section{Literature Review}

Sharon Gray Weiner of Vanderbilt University provided an excellent synthesis of the research on "what is known about the characteristics and leadership style of university librarians and academic library directors." She also has discussed studies that address "recruitment, leadership potential identification, career development, roles and responsibilities, and characteristics and management style." As she showed, "leadership influences a library's effectiveness, institutional role, and adaptability."16

James F. Williams II of the University of Colorado at Boulder and Mark D. Winston of Rutgers University maintained that, for a long time, research conducted in the private sector has probed the competencies (traits and abilities) that successful leaders possess. Those competencies can be "used as a basis for strengthening an organization's leadership team and determining the types of educational and leadership development opportunities that are needed for future leaders." 17

An issue of Library Trends (summer 2004), which is devoted to "organizational development and leadership," contains several articles on the role of leaders and the acquisition of critical leadership traits. In particular, Shelley E. Phipps of the University of Arizona library regarded library leaders as those who, in part, facilitate "a shared leadership system" that requires "a significant investment in leadership training." ${ }^{18}$ Consultants Florence M. Mason and Louella V. Wetherbee, who analyze various training programs for library leadership, showed that such programs try to develop participants' leadership skills and "focus on leadership styles, self-discovery, and [an] emphasis on skill-building." ${ }^{19}$ They encourage "the development of a clear and broadly accepted set of general library leadership competencies for all types of library settings" and "the vigorous promotion of these competences in library training and educational venues of all types." 20 The study reported here continues the journey to forming a set of widely accepted traits that can be learned or refined.

Outside library and information science, as suggested above, there is increased focus on EI. For example, one study shows that business leaders rank EI traits as more important than traditional leadership traits for the successful leader to posses. ${ }^{21}$ Of particular importance are developing a shared vision, relationship building, employee development, adaptability, optimism, empathy, and self-awareness.

\section{Procedures}

This study consists of two parts: (1) an analysis of job advertisements for library directors and (2) a survey of library directors. Job advertisements tend to reflect the perspectives of the search committee and those traits on which committee members can agree as important for the present and near future. The need for particular traits can shift over time and from situation to situation.

The authors performed a content analysis of all job advertisements appearing in College E Research Libraries News from 2000 through 2004 for the position of library director in institutions in either the Association of Research Libraries (ARL) or the Association of College and Research 
Libraries (ACRL), for any mention of leadership. Leadership was defined as covering one or more of the traits identified in the survey portion of the study (and shown in tables 1-5).

For the second part, university library directors serving in the ARL became the study population. Omitting those institutions in which the position was then listed as open (managed by an interim director), the study population totaled 102 individuals, of whom 70 responded to the five-page questionnaire (response rate of $68.6 \%$ ).

Eight respondents were selected for follow-up interviews conducted either in person or by telephone. Those selected for the interviews provided geographical, length of tenure as an ARL director, and gender balance. The purpose of the interviews was to gain different perspectives on leadership and some of the study's major findings.

Excel was used for data entry and analysis for both the content analysis and survey portions of the study.

\section{Content Analysis of Job Advertisements}

The authors created five lists, each of which corresponded to one of the categories of EI. The items in each list corresponded to the tables used to characterize EI in the survey portion of the study. For self-awareness (understanding of one's self and one's effect on others), the job advertisements identified only five traits. A "record of proven innovative and effective leadership" was mentioned in 45 (19.9 \%) of the 226 advertisements. "Respect for individuality and diversity" appeared in a distant second place (ten times). Rounding out the list was:

- "Respect scholarship, learning, and teaching" (3)

- "Articulate" (2)

- "Enthusiastic" (2)

For self-regulation (think before acting and self-control), only four traits were mentioned. A "broad knowledge of issues" appeared most often, but only in ten instances. Completing the list were "comfortable with change" (6), "think 'outside the box' (in new and creative ways applicable to the problem)" (4), and "flexible in adapting to change or overcoming obstacles" (1).

The third category, motivation (pursue goals with energy and persistence, passion for work, and getting others to pursue a shared vision), produced more variety, with the following items listed:

- "Visionary - able to build a shared vision and rally others around it" (46)

- "Commitment to job, organization, institution, and profession" (18)

- "Creative" (17)

- "Good oral and written presentation skills" (15)

- "Create an environment that fosters accountability" (5)

- "High energy level" (5)

- "Motivate people to develop and adhere to a shared vision" (1)

- "Encourage reasonable risk taking" (1)

Two items appeared twice in the "other" category: "generate support" and "achieve goals."

For the fourth category, empathy (ability to understand the emotional makeup of others and the skill to treat people according to their emotional reactions), only two items appeared: "good interpersonal/people skills" was mentioned twenty-seven times and "cross-cultural sensitivity and record of achievement" appeared only once.

The final category, social skill (ability to manage relationships and build networks, and ability to find common ground and build rapport), had ten traits that appeared in the advertisements. "Collaborative" was listed most frequently (35), followed by "advocate for librarians' role in higher education" (13), "develop and foster partnerships" (8), "help participants in meetings, consortia, and cooperative endeavors to be results oriented (6), "lead in a shared decision-making environment" (5), "consensus building in carrying out strategic direction" (4), 
"expertise in building and leading teams" (4), and "enabler and facilitator" (3). Both "good people networking skills" and "resonance (inspiring people to work together to solve problems, inspiring excellence)" appeared only once, as did an item in the "other" category: "serve as a role model of desired behavior."

\section{Survey Findings}

Characterization of Emotional Intelligence As previously mentioned, EI has been characterized in terms of five categories: self-awareness, self-regulation, motivation, empathy, and social skill. The first five questions took each category and asked respondents if they had any traits to add and then to identify the five most important ones. Because four respondents did not confine their rating to only five items, their responses are excluded from the following analysis; therefore, this portion of the survey had sixty-six respondents $(64.7 \%)$.

For the first category, self-awareness, "cognitive ability to deal with complex

\begin{tabular}{|c|c|c|c|}
\hline \multicolumn{4}{|l|}{$\begin{array}{c}\text { TABLE } 1 \\
\text { Self-awareness }\end{array}$} \\
\hline Trait & Total & Rank & Average \\
\hline Able to hone one's ability & 3 & & 3.333 \\
\hline Absence of ego (or ego is not a barrier) & 8 & & 2.125 \\
\hline Articulate & 18 & & 2.777 \\
\hline Assertive & 4 & & 4.25 \\
\hline Challenge assumptions & 12 & & 2.416 \\
\hline Cognitive ability to deal with complex scenarios/situations & 34 & 1 & 3.764 \\
\hline Drive for task completion & 5 & & 4.0 \\
\hline Enthusiastic & 19 & & 3.315 \\
\hline Intuition & 9 & & 2.888 \\
\hline Know where he or she is going - taking the organization & 26 & 3 & 2.115 \\
\hline Narcissism (an acceptable level) & 1 & & 3.0 \\
\hline $\begin{array}{l}\text { Realistic understanding of oneself: emotions, strengths, } \\
\text { weaknesses, needs, and drives }\end{array}$ & 32 & 2 & 2.437 \\
\hline $\begin{array}{l}\text { Recognize how one's feelings affect others and one's job } \\
\text { performance }\end{array}$ & 13 & & 3.153 \\
\hline Resilient & 13 & & 3.692 \\
\hline Respect individuality and diversity & 23 & 5 & 3.652 \\
\hline Respect scholarship, learning, and teaching & 1 & & 2.909 \\
\hline Self-confident & 20 & & 2.24 \\
\hline Sense of humor & 25 & 4 & 4.4 \\
\hline Sense of personal identity & 4 & & 4.0 \\
\hline Show initiative & 12 & & 3.833 \\
\hline Tenacity & 8 & & 3.25 \\
\hline Willingness to tolerate frustration and delay & 5 & & 3.8 \\
\hline Record of proven leadership & 12 & & 2.75 \\
\hline Other & 4 & & \\
\hline
\end{tabular}




\begin{tabular}{|c|c|c|c|}
\hline \multicolumn{4}{|l|}{$\begin{array}{c}\text { TABLE } 2 \\
\text { Self-regulation }\end{array}$} \\
\hline Trait & Total & Rank & Average \\
\hline $\begin{array}{l}\text { Ability to figure out what is going on without having to be } \\
\text { told }\end{array}$ & 14 & & 2.571 \\
\hline Ability to compromise & 12 & & 4.166 \\
\hline Ask the "right"/ "tough" question & 6 & & 3.166 \\
\hline Broad knowledge of issues & 12 & & 2.416 \\
\hline Comfortable in making judgment calls & 22 & 3 (tie) & 2.909 \\
\hline Comfortable with ambiguity & 22 & 3 (tie) & 2.909 \\
\hline Comfortable with change & 13 & & 3.307 \\
\hline Diplomatic & 14 & & 2.865 \\
\hline Endurance & 0 & & 0 \\
\hline Evenhanded & 4 & & 4.5 \\
\hline Flexible in adapting to change or overcoming obstacles & 20 & 4 & 2.95 \\
\hline Handle stress well & 12 & & 3.583 \\
\hline Honesty & 15 & & 2.866 \\
\hline Initiative & 4 & & 2.75 \\
\hline $\begin{array}{l}\text { Innovative, seeks out, and acts on challenges and new } \\
\text { opportunities }\end{array}$ & 15 & & 2.733 \\
\hline Integrity & 26 & 2 & 2.615 \\
\hline Open-minded & 11 & & 2.727 \\
\hline Propensity for reflection & 8 & & 3.375 \\
\hline Realistic organizational awareness & 13 & & 3.615 \\
\hline Receptivity to change & 5 & & 3.6 \\
\hline Sense of perspective & 8 & & 3.0 \\
\hline Skill at diagnostic, strategic, and tactical reasoning & 17 & 5 & 2.823 \\
\hline $\begin{array}{l}\text { Stable temperament and ability to maintain an emotional } \\
\text { balance under constant tensions }\end{array}$ & 29 & 1 & 2.724 \\
\hline $\begin{array}{l}\text { Think outside the box (in new and creative ways } \\
\text { applicable to the problem) }\end{array}$ & 10 & & 2.9 \\
\hline Trustworthy & 10 & & 2.8 \\
\hline Other & 2 & & \\
\hline
\end{tabular}

scenarios/situations" was rated as most important, followed by "realistic understanding of oneself: emotions, strengths, weaknesses, needs, and drives"; "know where he or she is going-taking the organization"; "sense of humor"; and "respect for individuality and diversity." (See "total" and "rank" columns in table 1.) Seven of the twenty-three traits were chosen no more than five times, with two ("narcissism [an acceptable level]" and "respect scholarship, learning, and teaching") mentioned only once. The remaining eleven traits were selected between eight and twenty times.

Three respondents added four "other" traits, three of which relate to leadership ("drive for continual self-improvement 
at a holistic level," "spiritual integrity and humility," and "ability to listen and delegate"). The fourth trait actually deals more with the position of director: "thick skin and a tolerance of loneliness."

Table 2 addresses the second category, self-regulation. Of the twenty-five items listed there, "stable temperament and ability to maintain an emotional balance under constant tensions" was ranked as most important," followed by "integrity." "Comfortable in making judgment calls" and "comfortable with ambiguity" tied for third position. "Flexible in adapting to change or overcoming obstacles" was ranked fourth, and "skill at diagnostic, strategic, and tactical reasoning" was ranked fifth. A number of the other rankings had tied positions, and seven items were not mentioned more than eight times. In fact, nobody chose "endurance." However, one respondent added one trait: "courage of convictions." Another director thought that "good listening skills" related to both "self-regulation" and "empathy."

The third category, motivation, consists of nineteen items. (See table 3.) The most important trait is "visionary - able to build a shared vision and rally others around it," followed by "motivate people to develop and adhere to a shared vision," "commitment to job, organization, institution, and profession," "articulate direction for the library," and "optimism (even in the face of failure)." Three other traits were chosen between twenty-one and twenty-six times, and another seven were mentioned between nine and fourteen times. The final four items were

\begin{tabular}{|c|c|c|c|}
\hline \multicolumn{4}{|l|}{$\begin{array}{c}\text { TABLE } 3 \\
\text { Motivation }\end{array}$} \\
\hline Trait & Total & Rank & Average \\
\hline Articulate direction for the library & 29 & 4 & 2.689 \\
\hline Accessible to others & 14 & & 3.571 \\
\hline Change/shape the library's culture & 21 & & 3.190 \\
\hline Commitment to job, organization, institution, and profession & 30 & 3 & 2.6 \\
\hline Create an environment that fosters accountability & 14 & & 3.785 \\
\hline Creative & 6 & & 3.0 \\
\hline Driven to achieve beyond expectations & 14 & & 3.428 \\
\hline Encourage reasonable risk taking & 26 & & 3.769 \\
\hline Figure out what is going on without having to be told & 5 & & 2.8 \\
\hline Good oral and written presentation skills & 11 & & 4.09 \\
\hline High energy level & 24 & & 3.0 \\
\hline Mobilize individual commitment & 10 & & 3.5 \\
\hline Motivate people to develop and adhere to a shared vision & 31 & 2 & 2.87 \\
\hline Nurture staff & 9 & & 3.333 \\
\hline Optimism (even in the face of failure) & 28 & 5 & 3.142 \\
\hline Tolerate some mistakes & 4 & & 3.5 \\
\hline Treat others as an equal & 9 & & 2.777 \\
\hline Understand small group dynamics & 3 & & 3.666 \\
\hline Visionary — able to build a shared vision and rally others around it & 36 & 1 & 1.583 \\
\hline Other & 1 & & \\
\hline
\end{tabular}




\begin{tabular}{|c|c|c|c|}
\hline \multicolumn{4}{|l|}{$\begin{array}{l}\text { TABLE } 4 \\
\text { Empathy }\end{array}$} \\
\hline Trait & Total & Rank & Average \\
\hline Attract, build, and retain talent & 46 & 2 (tie) & 2.543 \\
\hline Comfortable with team culture & 24 & & 3.208 \\
\hline Cross-cultural sensitivity and record of achievement & 12 & & 3.416 \\
\hline Exercises good judgment & 36 & 4 & 3.75 \\
\hline Good interpersonal/people skills & 46 & 2 (tie) & 2.782 \\
\hline Good listener & 33 & 5 & 2.5757 \\
\hline Interested in others & 18 & & 3.333 \\
\hline Keep organization focused on high-quality service & 37 & 3 & 3.27 \\
\hline Thoughtfully consider the feelings of others & 14 & & 3.571 \\
\hline Treat people with dignity/ respect & 54 & 1 & 2.648 \\
\hline Other & 5 & & \\
\hline
\end{tabular}

chosen between three and six times. One respondent added one attribute - "genuine belief in the abilities of, and the good faith in, others in the organization." The rationale for inclusion of this item is the "need to pursue goals and build teams."

The fourth category, empathy, contained eleven items, six of which were among those identified as most important. (See table 4.) There was widespread consensus that "treat people with dignity/ respect" was the first choice, followed by "attract, build, and retain talent" and "good interpersonal/people skills," which tied for second position. Rounding out the other most important choices were "keep organization focused on high-quality service," "exercises good judgment," and being a "good listener." Except for "comfortable with team culture," which was chosen twenty-four times, the remaining items were selected between twelve and eighteen times.

Five respondents identified other traits to add. Their choices included:

- "Ability to understand, anticipate, and harness native behaviors or approaches of staff (i.e., typical modes of reading and approaching problems)"

- "Wide range of work experiences in different sizes of organizations and different job levels (this exposes a person to variety and promotes empathy and respect)"

- "Give praise generously"

- "Being open-minded"

- "Having integrity"

Table 5, which highlights the social skill category, shows that "ability to function in a political environment" was mentioned more often than any trait in the other categories. The other most important social skills were "effective in leading change," "develop and foster partnerships," "collaborative," "build rapport with a wide circle of people," and "resonance (inspiring people to work together to solve problems, inspiring excellence)." The other thirteen traits were chosen between four and twenty times, with there being four instances of tied ranks. "Friendly (with a purpose)" was the least selected trait. Only one respondent suggested an additional trait-" "serve as a role model of desired behavior."

Because respondents were asked to identify the five most important traits for each table on a scale ranging from " 1 " (most important) to " 5 " (least important), the "average" column confirms the findings presented above. The average (mean) takes into account the respondents' ratings. In table 1, for instance, "cognitive ability to deal with complex scenarios/situations," 
which ranked first among the traits, had an average score of 3.764 (for 34 respondents). On the other hand, "drive for task completion" had an average of 4.00 , but only five respondents selected it. Thus, interpretation of the average must factor in the number of respondents selecting it.

\section{Learned Proficiency with the Traits}

Two often-asked questions are:

1. To what extent does knowledge about leadership (e.g., leadership theory, styles, and traits) transfer into practice so as to create, develop, or enhance the abilities of an individual?

2. How might those traits be best learned (an acquired skill) or enhanced?
Fifty $(71.4 \%)$ respondents addressed the questions. Differences of opinion emerged about which traits could be acquired or developed. Some thought that most or all of them could; others disagreed and maintained that individuals could learn a subset (e.g., listening ability, team-building skills, and effective meeting management), but not traits such as being humorous. More than likely, the subset that could be learned does not relate to someone's personality characteristics that involve unlearning and then relearning particular traits. One respondent thought the traits "are difficult to learn" and that most of EI is "nature and cannot be nurtured." However, she

\begin{tabular}{|c|c|c|c|}
\hline \multicolumn{4}{|l|}{$\begin{array}{c}\text { TABLE } 5 \\
\text { Social Skill }\end{array}$} \\
\hline Trait & Total & Rank & Average \\
\hline Ability to function in a political environment & 43 & 1 & 2.186 \\
\hline Ability to gather outside resources & 20 & & 3.1 \\
\hline Advocate for librarians' role in higher education & 11 & & 3.454 \\
\hline $\begin{array}{l}\text { Bring issues of broad importance to the academic community, } \\
\text { fostering wide discussion and action, when appropriate }\end{array}$ & 19 & & 3.210 \\
\hline Build rapport with a wide circle of people & 21 & 5 (tie) & 3.0 \\
\hline Collaborative & 23 & 4 & 2.956 \\
\hline Consensus building in carrying out strategic direction & 12 & & 3.5 \\
\hline Develop and foster partnerships & 26 & 3 & 3.269 \\
\hline Effective in leading change & 27 & 2 & 2.518 \\
\hline Enabler and facilitator & 11 & & 3.181 \\
\hline Entrepreneurial & 10 & & 3.4 \\
\hline Establish credibility with colleagues & 17 & & 3.352 \\
\hline Expertise in building and leading teams & 10 & & 4.1 \\
\hline Friendly (with a purpose) & 4 & & 4.75 \\
\hline Good people networking skills & 12 & & 3.333 \\
\hline $\begin{array}{l}\text { Help participants in meetings, consortia, and cooperative } \\
\text { endeavors to be results oriented }\end{array}$ & 7 & & 3.0 \\
\hline Lead in a shared decision-making environment & 20 & & 2.5 \\
\hline Persuasiveness & 9 & & 3.0 \\
\hline $\begin{array}{l}\text { Resonance (inspiring people to work together to solve prob- } \\
\text { lems, inspiring excellence) }\end{array}$ & 21 & 5 (tie) & 2.904 \\
\hline Other & 1 & & \\
\hline
\end{tabular}


recognized that there might be exceptions to this generalization.

One director inserted this caution: "It is much like learning [to play] a musical instrument. Some with talent can truly master a trait, others without talent can get better by working at it but may never truly master a particular capacity. And others are 'talented' enough that they naturally succeed in some areas." In effect, individuals must have some natural ability related to leadership. They also need to be observant, be receptive to learning and change, and have opportunities to build the necessary experience. Naturally, not everyone will be a successful leader.

Respondents suggested various options for acquiring the traits, including experience (e.g., teaming experience); collegial observation; mentoring and coaching; self-education (reading); course work; attending leadership institutes, workshops, and seminars; test taking (for the Myers Briggs test for creating self-awareness); and shadowing others. As one director noted, "A person can develop some skills for cultivating partnerships and bringing along results-oriented efforts in meetings, consortia, and cooperative efforts through training and observation of highly effective people. ... [M]any of these attributes are learned through experience." Course work, however, was viewed as perhaps least effective because it might not enable participants to learn from experience.

\section{Recognition as a Leader}

One question asked whether the respondents know any one person within academic librarianship who best exemplifies the highlighted leadership traits. The intent of the question was to elicit examples and not seek comprehensiveness. Furthermore, individuals might not be regarded as general leaders in the profession but, rather, as leaders on specific issues and problems such as intellectual property rights, entrepreneurship, access to government information, scholarly communication (e.g., publishers' pricing policies), collaboration, political skills, and group processes. Within this context, thirty-seven directors (52.9\%) identified one or more leader. The thirty-four individuals mentioned included ARL directors, colleagues at the specific institution, or individuals in other libraries (e.g., a community college or a library in another country); one director even added himself to the list. The names that appeared most frequently were James Neal of Columbia University, ${ }^{22}$ Ann Wolpert of MIT, and Betsy Wilson of the University of Washington.

\section{Extent to Which Institutions Seek Leaders}

To ascertain the directors' perspective on the leadership traits that institutions seek when they hire new directors, the final question inquired whether those individuals who make the hiring decision want risk takers and leaders. On the five-point scale with " 1 " being "strongly agree" and "4" being "strongly disagree (" 5 " equaled "no opinion"), the average was 2.66 and forty-two $(60 \%)$ circled either "strongly agree" or "agree"; sixteen answered either "disagree" or "strongly disagree" (22.9\%). Twelve (17.1 \%) ventured "no opinion."

As the respondents noted, it is difficult to generalize across institutions and the specific needs of institutions at the time of a hiring. There was agreement that institutions seek leaders, but there was far less concurrence about the need for risk takers; some endorsed risk taking and others rejected it. Two directors inserted a qualification - the search for "calculated risk takers." One supporter of risk taking remarked:

It has been my experience that the provosts who have hired me were definitely looking for a risk taker and leader. That was apparent in the questions they asked my colleagues whom they knew. It was also apparent in the dinner conversations I had with each provost before I was hired and then conversations after I 
was hired. In the ARL positions in which I have served, the provosts wanted someone who could not only come in to deal with and change dysfunctional organizations [libraries], but also to bring them back to good health and service. A change agent is always a risk taker; you have no choice because implementing change always involves some kind of risks. (I would also say that ARL colleagues I know very well were probably hired because of their reputations for taking risks and leadership.)

"Typically," one director pointed out, "the successful candidates have been risk takers and leaders in ... other settings, but 'fit' rather than 'trait' drives the final selection locally." There is often a "personality fit" - fits well in the organization's culture-and "good chemistry with the person to whom he or she reports."

The opposite viewpoint is that "the academy is risk averse and built on consensus and tradition." Furthermore, "if a library has been administered by someone tyrannical, the person making the hiring decision may need to focus on hiring a 'healer' rather than a risk taker-the library may need to get through the healing before it is ready to venture into risks." Thus, those making hiring decisions might seek "safe" candidates, the opposite of what they had or someone who will not "rock the boat." "They do not want someone who will create controversy, internally or externally, which might land on their desk." This group of directors also commented:

The majority of the time, the people who do the hiring for ARL directors are not themselves directors. They rarely understand the full scope of traits and skills required of directors. Their response to candidates is highly situational, that is, how bad (or good) are things at that library already. If things are bad, the search committee will look for a risk taker who will fix messes and bring change. If things are wonderful and the faculty love the library, the search committee will be cautious and look for someone conservative who will maintain the status quo. This is true even if one or two working librarians are on the committee, since they (1) don't really understand the director's job either and (2) have no power on the search committee. A search committee may sometimes perceive a leader as someone who will focus too much on external activities and not spend enough time on the home front or as someone who will not listen effectively to the individual "needs" of staff or faculty. The challenge when one is a candidate is often to figure out quickly whether one is dealing with a conservative or a venturesome search committee.

Most of those who make the final hiring decisions for deans/directors of ARL libraries are seeking people who are knowledgeable, articulate, cooperative, and sometimes even compliant. They want people who report to them to be effective, but not especially demanding of time, attention, and resources. They value good citizenship to the institution and discourage those who strongly advocate for their unit or are aggressively independent. Increasingly, they want deans/directors who are experienced fundraisers. Especially in the largest libraries, they rarely hire potential rather than experience.

One director disagreed with the proposition that those making the hiring decision consider either leadership or risk taking:

Librarians, by their training and experience, do very well in these areas because they alone on the academic side are promoted for these traits. LIS education stresses that most li- 
brarians will be managers of people, money, and resources. By the time a librarian becomes a director, he or she has had extensive experience in all areas of management. This is not true of deans and department heads in academic units. Librarians self-select and advance leaders so that the pools for these positions are strong, not because the search process seeks leadership and risk taking.

In addition to leadership, institutions often seek "a good fundraiser, a trustworthy colleague, and someone who will represent the institution well." Furthermore, they want individuals with good people skills, who are innovative and who will get along well with the faculty and administration, including the person to whom the director will report. One director noted: "Smart academic leaders want innovative and successful leaders for their libraries. Often they seek out individuals who can change the organization and lead it into the future. On the other hand, I know provosts who intentionally avoid such risk takers and want status quo."

\section{Interviews}

The purpose of the interviews was to probe the study's research questions and determine whether a library leadership crisis looms. ${ }^{23}$ The directors did remark that the position is about "moving an organization forward; it is not about money and power." Being a director is "political and hard," and it is "stressful" and requires "knowing a little about many areas," a breadth of knowledge, the ability to "fix problems," to function without praise, to think on one's feet, to listen, to synthesize what one hears and reads; and maintain the "big picture-understand how all things come together." One director believed that the profession has been successful in developing and promoting people of color to managerial positions, "but not at the rate it should to match the nation's demographics." The critical traits associated with starting a new directorship, she thought, are respect and trust, gaining the respect of the staff and getting the staff to "trust that I want the library to provide the best service and to hold me accountable if I break that trust." She also emphasized the importance of patience (combined with persistence) as the director seeks to change the organizational culture.

Another director pointed out that "You choose which traits to showcase at a particular time" and that changing times and circumstances might require different ones. For the directors interviewed, attracting talented individuals to a directorship is less of a concern that finding good people to become department heads. Many librarians, they commented, have no long-term interest in management, perhaps preferring "to be project heads." Such positions are short term with clearly defined dates and deliverables, and they want neither the responsibility of a fulltime position in management nor their "life consumed by work." Critical issues confronting the profession, therefore, are to "get more good librarians to take responsibility and assume authority."

There was consensus that the university community is often unaware of what directors actually do and how complex the position is. One interviewee commented that upper-university administrators think of the library in terms of the time when they used to conduct research and do not associate libraries with many issues with which they now deal.

When the questions centered on the selection process for new directors, a common comment was: "A typical search committee consists of faculty, the director of information technology, and some working librarians. Neither these librarians nor the faculty are likely to be aware of what directors do." This director characterized two types of search committees:

\section{Cautious ones that want to} maintain the status quo. The members examine and compare the candidates line by line with the job advertisement. 
2. Adventitious ones that are more willing to be innovative and flexible. They might even bring in consultants to help in the review process.

In either instance, a key question is, How well do committee members get along? Another director expanded on the two types by noting that institutions may seek the opposite of the type of director they are replacing. However, upon arrival at the institution, the new director might turn to members of the search committee, "as you figure they helped to get you hired."

A couple of directors thought they possessed all the traits; the others believed that nobody could master all of them and that the senior management team, as a whole, would have the set. It is important, they stressed, that senior managers constantly engage in self-examination and seek to improve themselves.

The interviewees did not believe there is any leadership crisis and that the pool of talented librarians for directorships is "no better and no worse than before." One of them remarked: "In research libraries the $80 / 20$ rule applies; 80 percent of the directors are good leaders and 20 percent are not." This is all the more reason for the profession, he maintains, to maintain a good pool of candidates and to give such individuals the necessary experiences from which to learn and master different leadership styles.

Another reason to maintain a strong pool of candidates for the position of library director, it was noted, is that more than half the current directors are estimated to retire between 2002 and 2010. Given the assorted complex issues relevant to academic libraries, library directors, more than ever, will need to manage their relationships with others - both those internal and external to the profession.

As to the path for becoming a leader, the directors emphasized the importance of gaining diverse experiences in libraries and learning from those opportunities. "The best learning situations are those that are long term and give opportunities for personal growth." One director cautioned: "Growth has to be associated with line authority. Flat organizations want leaders at the senior level who have had line authority." Those interviewed highlighted mentoring, involvement in professional associations, and attending leadership institutes. A director added participation in consortia to which the library is a member; such consortia might deal with issues that cut across different campuses as part of a state university system. Involvement in consortia provides contacts and information as well as affords opportunities to engage in problem solving.

"Nurturing," one director commented, "is the role of both the director and AULs [associate or assistant library directors]. Some individuals are more comfortable working with one than the other. Because the director has the final say about salary, and perhaps about tenure, some librarians will prefer mentoring from the AULs." She also pointed out that one purpose of mentoring is to connect "people to the profession" and that "there is more than one way to do things; there is often no single answer."

\section{Discussion}

Three categories (self-awareness, selfregulation, and motivation) relate to "selfmanagement"; the other two (empathy and social skill) cover "managing relationships with others." For self-management (tables 1-3), "visionary - able to build a shared vision and rally others around it" (table 3) had the lowest average (1.583) among those most frequently identified, which means that more respondents were likely to rate it as most important. "Stable temperament and ability to maintain an emotional balance under constant tensions" (table 2) was second (average: 2.724), followed by "cognitive ability to deal with complex scenarios/situations" (table 1; average: 3.764). Using 3.764 as a general guide, all the highly ranked traits in tables 2 and 3 had a smaller average. Clearly, there is 
greater consensus on self-regulation and motivation than on self-awareness.

Turning to the other grouping (tables 4 and 5), "managing relationships with others," the most highly selected traits all had an average of less than 3.764. Among all the frequently mentioned traits (all five tables), the greatest consensus was on the importance of "visionary - able to build a shared vision and rally others around it" (table 3) and "ability to function in a political environment" (table 5; average: 2.186).

\section{Reorganization of Traits}

Only one director suggested a reorganization of the tables. This person pointed out that "respect for individuality and diversity" should be moved from the self-awareness category to the empathy category. The trait, "broad knowledge of issues," would fit the self-regulation category better if it were reworded as "ability to contextualize a given situation," which might mean a broad knowledge of issues, but "the real point is the ability to think before acting because one is aware of the larger picture." Good listening skills," it was suggested, might relate to both selfregulation and empathy.

\section{Job Advertisements}

A tertiary research question is, Do the traits identified in the job advertisements match the survey rankings? According to study findings, they do not! For the self-awareness category (table 1), the job advertisements were concerned mostly with objective measures of success (e.g., "proven record of innovative and effective leadership" [ranked the highest]). None of the advertisements mentioned individuals who had a "realistic understanding of oneself" (ranked second by the directors), "knowing where he or she is going - taking the organization" (ranked third), or even individuals who had a "sense of humor" (ranked fourth). This is particularly interesting because laughter and smiling are powerful creators of resonance. ${ }^{24}$

Likewise, for self-regulation (table 2), none of the advertisements mentioned individuals with a "stable temperament" or the other highly ranked traits. The advertisements listed having a "broad knowledge of issues" as most important; yet, only twelve directors chose this among their top characteristics.

In the third category, motivation (table $3)$, there appears to be more similarity between the advertisements and the director rankings. The directors considered "visionary" as the most important trait, which appeared in fifteen advertisements. "Commitment" appeared most frequently in the advertisements and the directors regarded it as third. Interestingly, optimism was ranked fifth by the directors, but this trait was not mentioned in the advertisements.

In the fourth category, empathy (table 4), "good interpersonal skills" appeared most frequently in the advertisements but, together with "attract, build, and retain talent," tied for second position in the director ratings. The directors placed "treat people with dignity and respect" first, "keep the organization focused on high-quality service" third, "exercises good judgment" fourth, and "being a good listener" fifth. Yet, the advertisements mentioned none of these traits.

With the last category, social skill (table $5)$, there was a divergence between the advertisements and the director ratings. The directors ranked "ability to function in a political environment" the highest, but the advertisements did not mention this trait. Being "collaborative" appeared most often in the advertisements, but the directors ranked it fourth.

\section{Comparison of Findings to Broader Literature}

An emotionally intelligent leader appears to have much in common with transformational leadership, another form of leadership. One way to look at transformational leadership is to contrast it with the concept of transactional leadership. Transactional leaders are power wielders; they guide or motivate their followers to establish and meet goals and to clarify role and task re- 
quirements. In contrast, transformational leaders have an interest in the personal development of followers. This is similar to the EI concept of empathy. Transactional leaders get what they want and followers get something their want; succinctly stated, this is the "carrot-and-stick" approach. The transactional leader pursues a cost-benefit, economic exchange to meet subordinates' current material and psychic needs in return for "contracted" services provided by the subordinate. Additionally, transactional leaders cannot sublimate their own needs to the organization's, but the transformational leader can. ${ }^{25,26}$ This is similar to the EI trait of "stable temperament and ability to maintain emotional balance."

Transactional leadership works well when maintaining day-to-day operations in stable environments. The problem with transactional leadership is that subordinates are not motivated to work toward a group goal unless a personal incentive is involved. Clearly, transactional leaders do not achieve the benefits of outstanding performance and their subordinates do not realize their potential.

Transformational leadership builds on transactional leadership. Similar to the EI leader, the transformational leader recognizes existing needs in potential followers but tends to go further, seeking to satisfy higher needs and to engage the full person or follower. ${ }^{27}$ The transformational leader can move followers to transcend their own self-interest for the good of the group or organization.

Transformational leaders provide individualized consideration and intellectual stimulation, and they possess charisma. They have special skills that allow them to provide a supportive environment while motivating followers to higher levels of personal action. A transformational leader inspires the members of the organization to achieve more than they thought possible. Consequently, transformational leadership shares many of the EI traits related to motivation.

It follows that a transforming leader acts to maximize the needs of followers.
Leadership also must stimulate the needs of the entire organization, constantly moving employees to higher-order needs. The term transformational stems from the ability to develop people as resources and to move them to a more satisfactory state of existence. ${ }^{28}$ By appealing to higher-order needs, the transformational leader generates subordinate commitment to achieving the organizational mission.

In reviewing the literature on transformational leadership, the following traits appear consistently: acting creatively, acting interactively (with vision), being empowered, passionate, and ethical. Creativity is revealed through challenging the status quo and seeking new ideas. Creative leaders see problems from different perspectives and are able to solve those problems. EI covers creativity and being visionary, and has variations of the other frequently mentioned traits.

Transformational leaders act as visionaries in that they work to achieve a shared vision. They empower their followers due to their ability to translate intention into reality and sustain it for the followers. This empowerment puts duality into motion; empowerment creates more empowerment, which in turn creates more power and allows followers to achieve their potential. The strength and compelling nature of this vision empowers the organization's members to excel.

A surprising element in the listing of traits is that the leader must have passion. ${ }^{29}$ Transformational leaders are passionate about their roles, tasks, responsibilities, and obligations to their staff. They forget their personal problems, lose a sense of time, and feel competent and in control. Without passion, there is no direction and vision is short-lived. Although the word passion did not appear as an EI trait, several characteristics are similar; for instance, "driven to achieve beyond expectations" involves being passionate.

Another defining characteristic that emerges repeatedly in the literature on 
transformational leadership is that the leader is an agent of change, a catalyst for change, but not a controller of change. ${ }^{30}$ Change emerges as an EI trait, for example, "change/shape the library's culture," "comfortable with change," and "flexible in adapting to change or overcoming obstacles."

\section{Research Agenda}

Instead of continuing to examine leadership traits in general, future research might probe different situations and identify any variations in the traits selected and used. Such research might take The Carnegie Classification of Institutions of Higher Education ${ }^{31}$ and, through the application of case studies, investigate those traits over time and determine any shifts in the most frequently occurring ones. In other words, how well do the general traits identified in this article hold over time and in different situations? Furthermore, within this context, are there differences in the occurrence of different traits by gender and other general variables?

Further research might look at other types of leadership than emotional intelligence, comparing the traits and reducing any overlap among them. Case study research might take individuals identified in this study or elsewhere as leaders and probe which traits they have and how they use them effectively. ${ }^{32}$ Furthermore, do staff and others concur with the characterization of certain individuals as leaders and any claim that directors possess certain traits?

\section{Limitations}

The authors recognize that the importance of specific traits may vary from situation to situation and institution to institution and that many respondents wanted to select more than five traits. Nonetheless, by focusing on a few, the authors had an opportunity to review and refine the emerging list.

\section{Conclusion}

Leadership might be defined in terms of emotional intelligence. Many aspects of this theory are similar to transformational leadership. As Goleman noted, EI "can be learned and improved at any age. In fact, ... on average, people's emotional intelligence tends to increase as they age. But the specific leadership competencies that are based on emotional intelligence don't necessarily come through life experience." ${ }^{33}$ He further observed: "Leaders who are motivated to improve their emotional intelligence can do so if they're given the right information, guidance, and support." 34

Leadership involves leading or influencing people to develop shared values, vision, and expectations based on shared principles and behaviors and to advance organizational effectiveness. In effect, "if a person cannot influence others, they will not follow that person; and if they will not follow, the person is not a leader." ${ }^{35}$ Still, few people possess every trait identified in the five tables, but those traits deemed most essential for EI and other leadership styles merit close scrutiny and development. For these reasons, it is important to identify the assorted traits that comprise EI and to see that aspiring leaders in library and other information fields cultivate the ones deemed most critical.

\section{Notes}

1. A. J. Anderson, course handout for LIS 404, library management (Dec. 11, 2000). Donald E. Riggs distinguishes between management and leadership in "The Crisis and Opportunities in Library Leadership," Journal of Library Administration ${ }^{\mathrm{TM}}$ 32, no. 3/4 (2001): 6-7. Steven R. Covey states that "leadership creates new paradigms. Management works within the paradigm. Leadership works on the system. You manage 'things'; but you lead people. Fundamental to putting first things first in our lives is leadership before management: 'Am I doing the right things' before 'Am I doing things right'?" Steven R. Covey, First Things First (New York: Simon \& Schuster, 1994), 27-28.

2. Anderson, Unpublished course handout. 
3. Riggs, "The Crisis and Opportunities in Library Leadership," 5.

4. J. Richard Hackman, Leading Teams: Setting the Stage for Great Performance (Boston: Harvard Business School Pr., 2002), 226.

5. Daniel Goleman, Emotional Intelligence (New York: Bantam Books, 1995).

6. _— "What Makes a Leader?" Harvard Business Review 82 (Jan. 2004), 82.

7. Ibid., 88 .

8. Peter Hernon, Ronald R. Powell, and Arthur P. Young, "Association of Research Libraries:

The Next Generation, Part One," College \& Research Libraries 62 (Mar. 2001): 116-45.

9. — "Association of Research Libraries: The Next Generation, Part Two," College \& Research Libraries 63 (Jan. 2002): 73-90.

10. (Nov. 2004): 538-63.

11. _ The Next Library Leadership (Westport, Conn.: Libraries Unlimited, 2003).

12. Mark D. Winston, editor, "Leadership in the Library and Information Science Profession: Theory and Practice," Journal of Library Administration ${ }^{\mathrm{TM}}$ 32, no. 3/4 (2001): 1-186.

13. Terrence F. Mech and Gerard B. McCabe, Leadership and Academic Libraries (Westport, Conn.: Greenwood Pr., 1998).

14. Goleman, "What Makes a Leader?" 91.

15. W. C. H. Prentice, "Understanding Leadership," Harvard Business Review 82 (Jan. 2004): 109.

16. Sharon Gray Weiner, "Leadership of Academic Libraries: A Literature Review," Education Libraries 26, no. 2 (Winter 2003): 5. For an additional identification of relevant writing on leadership in academic and public libraries, see Hernon, Powell and Young, The Next Library Leadership.

17. James F. Williams II and Mark D. Winston, "Leadership Competencies and the Importance of Research Methods and Statistical Analysis in Decision Making and Research and Publication: A Study of Citation Patterns," Library \& Information Science Research 25 (2003): 388. See also Jim Intagliata, David Ulrich, and Norm Smallwood, "Levering Leadership Competencies to Produce Leadership Brand: Creating Distinctiveness by Focusing on Strategy and Results," Human Resource Planning 23, no. 3 (Sept. 2000). Available online from Expanded Academic ASAP Plus.

18. Shelley E. Phipps, "The System Design Approach to Organizational Development: The University of Arizona Model," Library Trends 53 (Summer 2004): 75, 77. See also P. Senger, "The Leader's New Work: Building Learning Organizations," Sloan Management Review 32 (1990): $7-23$.

19. Florence M. Mason and Louella V. Wetherbee, “Learning to Lead: An Analysis of Current Training Programs for Library Leadership," Library Trends 53 (Summer 2004): 187-217.

20. Ibid., 215.

21. Jennifer J. Salopek, “Social Intelligence," T + D 58, no. 9 (Sept. 2004): 17.

22. See Gregg Sapp, "James Neal on the Challenges of Leadership: An 'LA\&M' Exclusive Interview," Library Administration \& Management 19, no. 2 (Spring 2005): 64-67.

23. Riggs, "The Crisis and Opportunities in Library Leadership," 16.

24. Daniel Goleman, Annie McKee, and Richard E. Boyatzis, Primal Leadership (Boston: Harvard Business School Pr., 2002), 19-32.

25. K. W. Kuhnert, "Transformational Leadership: Developing People through Delegation," in Improving Organizational Effectiveness through Transformational Leadership, ed. B. M. Bass and B. J. Avilio (Thousand Oaks, Calif.: Sage, 1994), 10-25.

26. Nancy R. Hoover, “Transformational and Transactional Leadership: An Empirical Test of a Theory." Paper presented at the annual meeting of the American Educational Research Association, Chicago, Apr. 1991. (ED 331 117).

27. James M. Burns, Leadership (New York: Harper \& Row, 1978), 9.

28. Ibid., 141. 1989).

29. Steven Covey, The Seven Habits of Highly Effective People (New York: Simon \& Schuster,

30. Bruce J. Avolio, "Leadership: Building Vital Forces into Highly Developed Teams," Human Resource Management Journal (1995): 10-15.

31. The Carnegie Classification of Institutions of Higher Education (Menlo Park, Calif.: Carnegie Foundation for the Advancement of Teaching, 2001).

32. See, for instance, the identification of leadership in Karin Wittenborg, Chris Ferguson, and Michael A. Keller, Reflecting on Leadership, CRL Publication 123 (Washington, D.C.: Council on Library and Information Resources, 2003).

33. Goleman, “Never Stop Learning," Harvard Business Review 82 (Jan. 2004): $28-29$.

34. Ibid., 29.

35. John C. Maxwell, Leadership 101 (Nashville, Tenn.: Thomas Nelson, Inc, 2002), 69-70. 